\title{
Dioscorea polystachya (Dioscoreaceae): A new record for India
}

\author{
Akramul Hoque ${ }^{1}$, P. Lakshminarasimhan² and D. Maity ${ }^{1 *}$ \\ ${ }^{1}$ Taxonomy and Biosystematics Laboratory, Department of Botany, University of Calcutta,35, Ballygunge \\ Circular Road, Kolkata - 700019, West Bengal, India. \\ 'Botanical Survey of India, Western Regional Centre, 7, Koregaon Road, Pune - 411001, Maharashtra, India. \\ *E-mail: debmaity@yahoo.com
}

\begin{abstract}
Dioscorea polystachya Turcz. (Dioscoreaceae), is reported here for the first time in India based on the collections from Mussoorie, Uttarakhand. The species is unique with its ternate or opposite, hastate-cordate leaves and zigzag staminate inflorescence axis. The species is illustrated and its detailed description, phenology, habitat and distribution are provided to aid easy identification.
\end{abstract}

Keywords: Dioscorea polystachya, Dioscoreaceae, Distribution, India, New record

\section{Introduction}

Dioscorea L., commonly known as yam, is of great economic value for its edible tuber as well as medicinal importance including source of steroidal saponins and used extensively in the industrial synthesis of cortisone and human sex hormones. Presently, the genus comprises c. 630 species, and widely distributed in tropical and temperate regions of both the worlds (Ting \& Gilbert, 2000; Mabberley, 2017).

While studying the herbarium specimens of Dioscorea housed at CAL and BSD as part of a revisionary study on the family Dioscoreaceae in India, the authors came cross some interesting unidentified Dioscorea specimens collected from Mussoorie hills, Uttarakhand. The plant is characterised by right twining, glabrous stems with hastate and often shallowly 3-lobed leaves arranged in whorls (ternate) and zigzag male spikes. The specimens were critically studied along with pertinent literature (Ting \& Gilbert, 2000; Raz, 2002), and identified as Dioscorea polystachya Turcz., a species native to Eastern Asia and cultivated for its edible tubers. According to Raz (2002) this species was planted in garden as an ornamental and became naturalised almost throughout North America. Present paper provides a detailed description and illustration along with notes on its habitat and uses.

Dioscorea polystachya Turcz., Bull. Soc. Imp. Naturalistes Moscou 7: 158. 1837; C. Ting \& M.G.
Gilbert in Z.Y. Wu \& P.H. Raven, Fl. China 24: 294. 2000; Raz, Fl. N. America 26: 483. $2002 . \quad$ Figs. 1,2

Shrubby vine; tubers vertical, cylindric. Stems twining right, terete, glabrous, unarmed. Leaves simple, ternate or opposite, alternate towards base; petioles $2-4 \mathrm{~cm}$ long, shorter than lamina with apical and basal pulvini; lamina 3-7(-16) $\times 2-7(-14)$ $\mathrm{cm}$, hastate or shallowly 3-lobed, base shallowly cordate or truncate, margins entire, apex shortly acuminate, slightly cartilaginous, coriaceous, glabrous, 7-veined; venation campylodromous, midvein and first pair of secondary veins reaching up to acumen; outermost vein biforked, restricted to lateral lobes. Male inflorescence a simple spike, 2-8, fasciculate, axillary, erect; rachis triangular, zigzag, winged at angles, $1-1.5 \mathrm{~cm}$ long, stiff, hairy, bearing 10-15 alternate, solitary flowers. Male flowers globose, sessile with narrow base, c. $2 \mathrm{~mm}$; bract single, ovate, $c .1 \times 0.8 \mathrm{~mm}$, apex acuminate, concave, hairy at base; bracteole single, sessile, ovate, c. $0.5 \times 0.4 \mathrm{~mm}$, apex acute, stiff, hairy. Tepals $6(3+3)$; outer 3 obovate, $1.8-2 \times c .1 .5 \mathrm{~mm}$, apex rounded, concave, outer surface hairy; inner 3 obovate-spathulate, c. $1.7 \times 1.2 \mathrm{~mm}$, smaller than outer, constricted at base, apex rounded or acute, outer surface hairy, inner surface with two narrow longitudinal ridges. Stamens 6, c. $0.9 \mathrm{~mm}$ long; outer 3 free; inner 3 epiphyllous, inserted at extreme base of inner tepals, all fertile; filaments stout, c. $0.3 \mathrm{~mm}$; anthers c. $0.6 \mathrm{~mm}$ long, 2-celled, introrse; connective flat with appendage at tip. Pistillodes saucer-shaped, $0.2-0.3 \mathrm{~mm}$. 


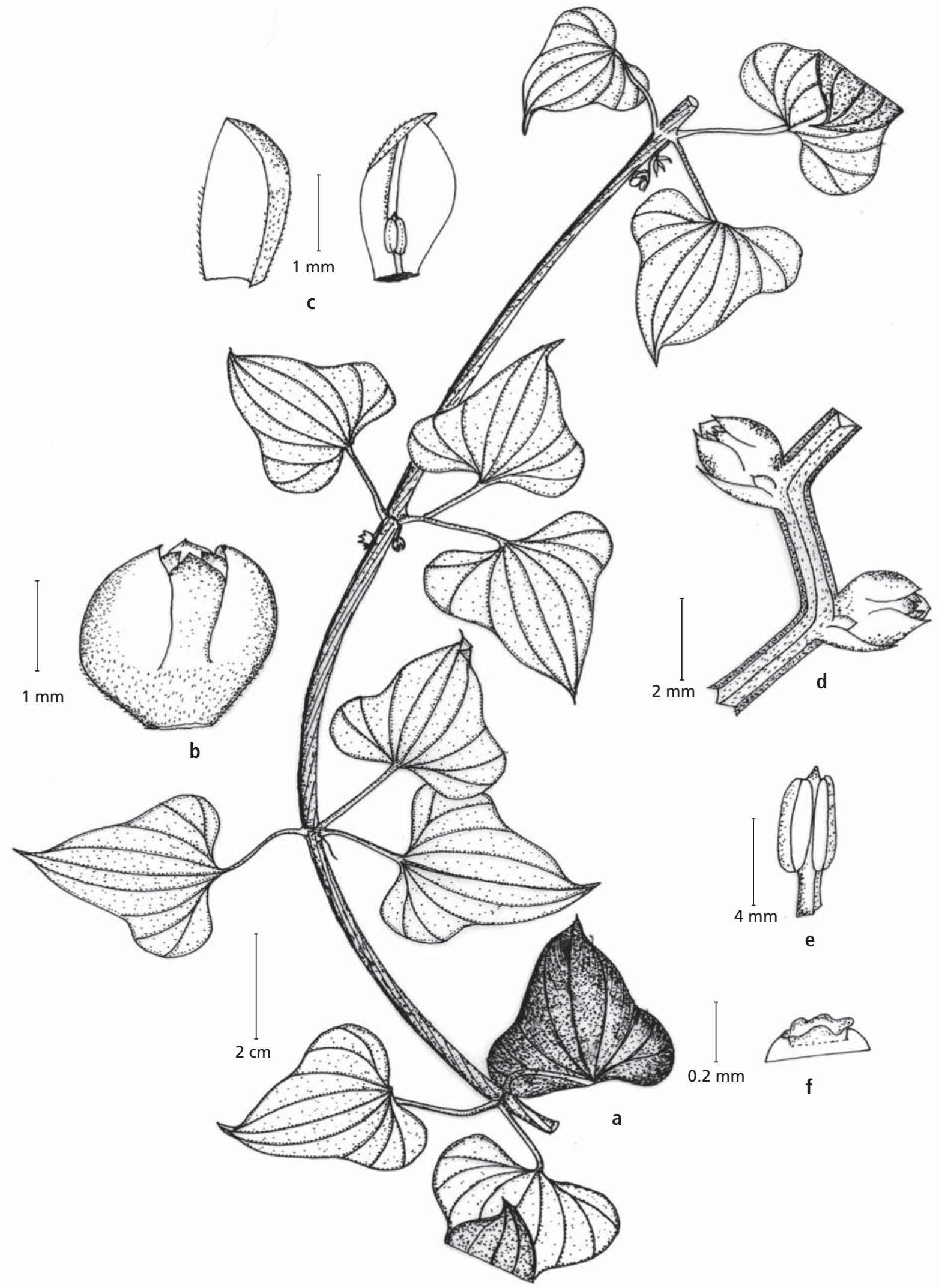

Fig. 1. Dioscorea polystachya Turcz.: a. Habit (in part, male plant); b. Male flower; c. Tepals; d. A portion of a flowering rachis; e. Stamen; f. Pistillode. 


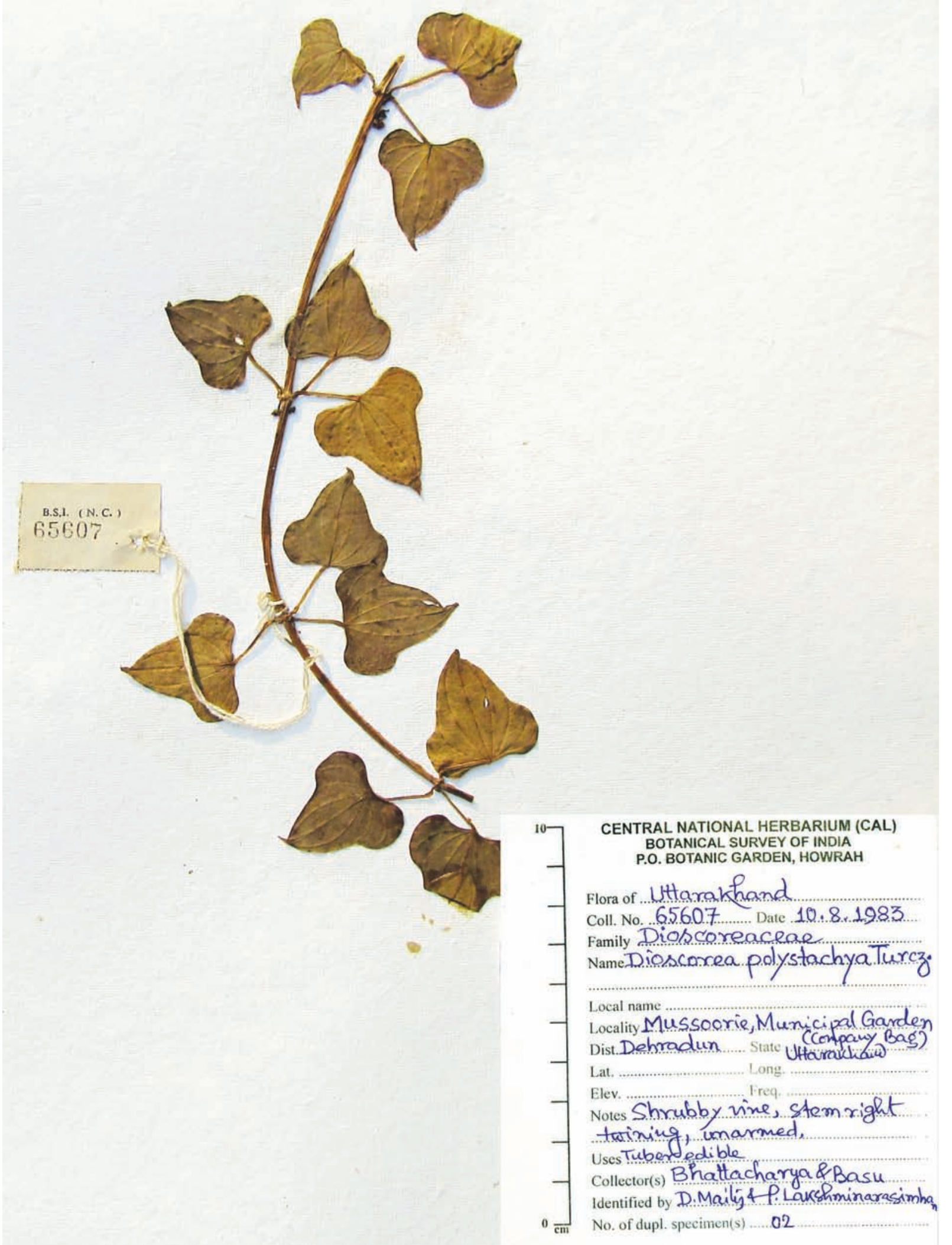

Fig. 2. Dioscorea polystachya Turcz. (Bhattacharya \& Basu 65607, CAL). 
Flowering: July-August.

Habitat: Grows on sunny rocky slopes of hills as wild, ascending to $2000 \mathrm{~m}$ elevation.

Distribution: America, China, India (Uttarakhand), Japan, Korea and Taiwan.

Specimens examined: INDIA, Uttarakhand: Mussoorie, Municipal Garden (Company Bag), 10.8.1983, Bhattacharya \& Basu 65607 (CAL, BSD).

Note: Only male plant is reported here. Underground part, bulbils, female flowers and fruits have not been collected so far from India. Dioscorea polystachya is sometimes superficially akin to $D$. oppositifolia by leaf characters, but differs in having usually whorled leaves at basal nodes, hastate lamina, campylodromous venation, zigzag male rachis and male flowers with narrow base with elongate torus.

Uses: The tubers are edible and can be eaten raw, while other yams must be cooked before consumption (due to harmful substances in the raw state). In Japanese cuisine, it is eaten raw and grated, after only a relatively minimal preparation; the whole tubers are briefly soaked in a vinegarwater solution to neutralize irritant oxalate crystals found in their skin. The raw vegetable is starchy and bland, mucilaginous when grated, and may be eaten plain as a side dish, or added to noodles.

\section{Acknowledgements}

The authors are grateful to Dr. Paramjit Singh, Director, Botanical Survey of India, for facilities and encouragement. One of us (AH) is thankful to Dr. P.K. Hajra, Ex-Director, BSI, for his valuable guidance. They also thank Dr. W. Arisdason, Central National Herbarium, Botanical Survey of India, Howrah, for critically going through the paper and also for his valuable comments.

\section{Literature Cited}

Mabberley, D.J. 2017. Mabberley's Plant-Book: A portable dictionary of plants, their classification and uses. Fourth Edition. Cambridge University Press, Cambridge.

Raz, L. 2002. Dioscoreaceae. In: Flora of North America Editorial Committee (eds.), Flora of North America North of Mexico. Vol. 26. Flora of North America Association, New York and Oxford. pp. 479-484.

Ting, C. \& M.G. Gilbert 2000. Dioscorea L. In: Wu, Z.Y. \& P.H. Raven (eds.), Flora of China. Vol. 24. Science Press, Beijing, and Missouri Botanical Garden Press, St. Louis. pp. 276-297.

Received: 6.4.2017

Revised and Accepted: 5.12.2017 